\title{
Analysis on three typical abnormal microstructures of overhead power line suspension clamps
} \author{
Wang $^{1}$ and Chun Liu ${ }^{1}$ \\ ${ }^{1}$ State Grid Hunan Electric Power Company Limited Research Institute, Changsha 410007, China \\ ${ }^{2}$ Hunan Xiangdian Boiler Pressure Inspection Center Co., Ltd, Changsha 410007, China \\ ${ }^{3}$ State Grid Xupu Power Supply Company, Huaihua, Hunan, 419300, China \\ ${ }^{4}$ State Grid Changde Power Supply Company, Changde, Hunan, 415001, China
}

Weike Liu ${ }^{1 *}$, Mengbao Zhou ${ }^{2}$, Jiarui Hu${ }^{1}$, Songqi $\mathrm{Wu}^{3}$, Xianhui $\mathrm{Cao}^{2}$, Jie Xiong ${ }^{4}$, Lian $\mathrm{Hu}^{2}, \mathrm{Yi} \mathrm{Xie}^{1}$, Chao Feng ${ }^{1}$, Jun

\begin{abstract}
This article lists three typical abnormal microstructures of overhead power line suspension clamps, including inclusion, flake graphite and cementite network. A series of tests including macro check, hardness measurement, composition tests, Energy-dispersive x-ray analysis and metallographic observation have been carried out. The experimental results showed that the causes of abnormal microstructures mainly include: high content of impurities, flake graphite blank and unfulfilled annealing heat treatment. It is suggested to strengthen the supervision on suspension clamps before using, and focus on the quality inspection of metallographic structure and composition.
\end{abstract}

\section{Introduction}

In the overhead power line, the suspension clamps is generally used to fix the conductor on the insulator string or to hang the overhead ground wire on the tangent tower. It can also be used to support the transposition conductor on the tangent tower or to fix the jumper on the tension and angle tangent tower. Under normal operation, the suspension clamp mainly bears the vertical load and horizontal wind load of the wires [1]. Overhang wire clamp is one of the most widely used products in overhead power lines. Because the safety factor selected in the line design of overhang wire clip is relatively large, the material used for overhang wire clip is low-end, size accuracy requirements are not high, coupled with the low price, so, extensive production and management are widely used for suspension clamps, and quality supervision mainly depends on the consciousness of suppliers. With the rapid development of power construction, the demand for the supply of dangling wire clips and other hardware has been greatly increased, and the number of new suppliers has also been greatly increased. However, the quality supervision and management has not been improved, resulting in hidden dangers in some suspension clamps in metal materials, especially the abnormal structure.

The material of suspension clamp is generally black heart malleable iron, and the normal microstructure is consist of ferrite and tempered graphite, as shown in Fig. 1. However, in the early failure analysis, three kinds of anomalies were found in the microstructure: inclusion, flake graphite and network cementite phase. In this paper, the causes of this three metallographic microstructure anomalies are analyzed in combination with failure analysis cases, and relevant measures are proposed from the perspective of metal technical supervision.

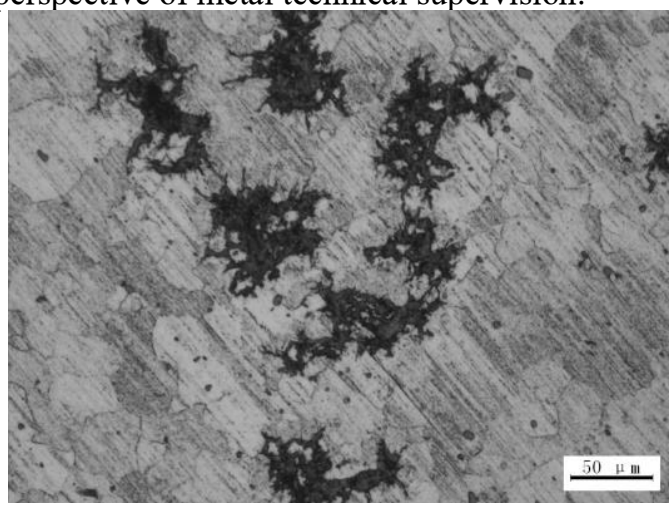

Fig. 1. normal microstructure of black heart malleable iron

\section{Experiment section}

The failed metal parts of isolation switch were collected from transformer substation in service. The morphologies and structures of the samples were analyzed by metallurgical microscopy (Zeiss microscope). The component measurement was conducted via desktop direct-reading spectrometer (Oxford corporation). The Brinell hardness test value were acquired from Brinell tester. The Energy-dispersive $\mathrm{x}$-ray analysis was conducted via energy dispersive spectrometer (Oxford corporation).

\footnotetext{
*Corresponding author: 543530832@qq.com
} 


\section{Results and discussion}

\subsection{Inclusion}

\subsubsection{Macro check}

The suspension clamp A broke in the groove where the u-screw was assembled, with a straight fracture, no obvious wear and plastic deformation, and a typical brittle fracture, as shown in Fig. 2. The suspension clamp was composed of Black heart malleable iron.

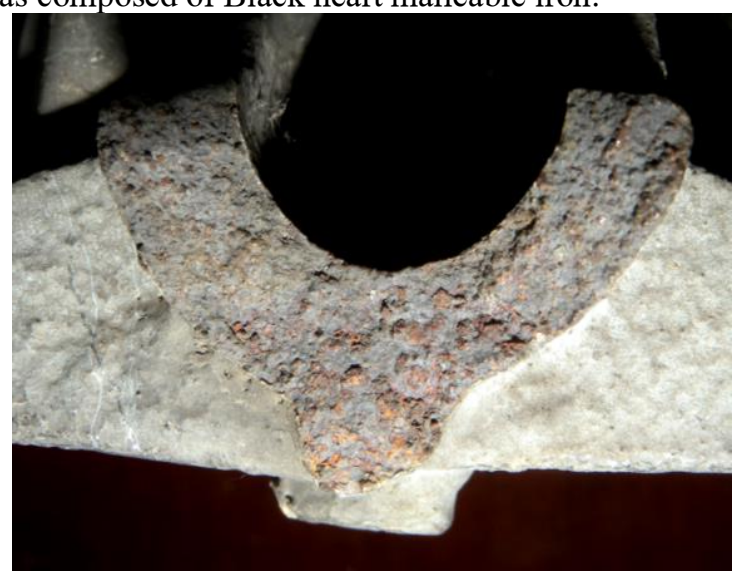

Fig. 2. The fracture morphology of suspension clamp A

\subsubsection{Component testing}

Table 1. Components of suspension clamp A.

\begin{tabular}{|c|c|c|}
\hline Element & Content $/ \%$ & $\begin{array}{c}\text { Recommended } \\
\text { range } / \%\end{array}$ \\
\hline $\mathrm{C}$ & 2.56 & $2.40-2.80$ \\
\hline $\mathrm{Si}$ & 1.35 & $1.20-2.00$ \\
\hline $\mathrm{Mn}$ & 0.56 & $0.30-0.60$ \\
\hline $\mathrm{S}$ & 0.26 & $\leqslant 0.20$ \\
\hline $\mathrm{P}$ & 0.10 & $\leqslant 0.10$ \\
\hline $\mathrm{Fe}$ & Remain & Remain \\
\hline
\end{tabular}

As illustrated in Table 1, the component of suspension clamp A was measured. The content of $\mathrm{S}$ exceeds the upper limit of recommended range. The other content of elements are in accordance with conventional requirements of black heart malleable iron.

\subsubsection{Hardness measurement}

The Brinell hardness of suspension clamp A was measured. The result was shown in Table 2. The test values are distributed in the range of $115 \mathrm{HB}$ to $136 \mathrm{HB}$ which conform to the standard requirements of DL/T768.1-2002 Malleable Iron.
Table 2. Brinell hardness of connecting lever.

\begin{tabular}{|c|c|c|}
\hline Test number & Test Value/HB & Standard/HB \\
\hline First & 115 & \multirow{2}{*}{$\leqslant 150$} \\
\cline { 1 - 2 } Second & 136 & \\
Third & 121 & \\
Fourth & 130 & \\
\hline Fifth & 127 & \\
\hline
\end{tabular}

\subsubsection{Microstructure analysis}

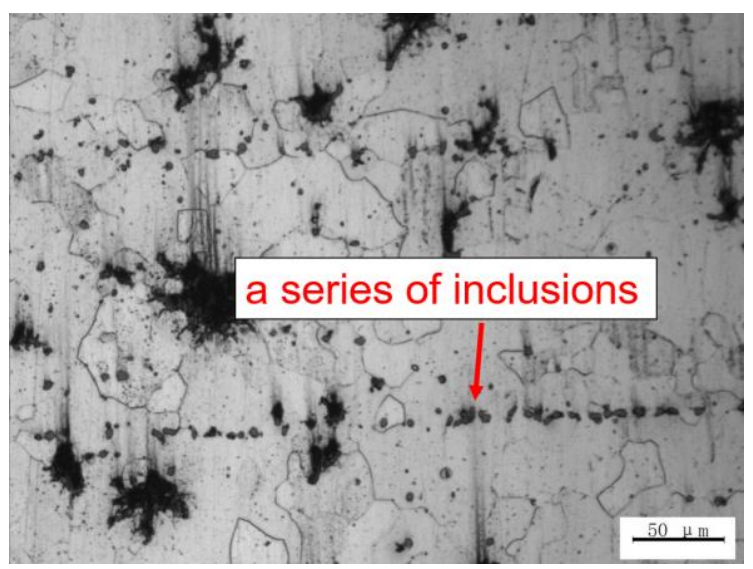

Fig. 3. The metallographic structure of suspension clamp A containing a series of inclusions.

The metallographic structure of suspension clamp A is consist of ferrite and tempered graphite, which meets the requirements of black heart malleable iron in the standard of GB/T 9440-2010 Malleable Iron [4].However, there are many inclusion of light gray particles in the metallographic structure, and they are connected into strings, as shown in Fig. 3.

\subsubsection{Energy-dispersive $x$-ray analysis}

Table 3. Composition of inclusion in suspension clamp A by EDS.

\begin{tabular}{|c|c|c|}
\hline Element & Wt. $/ \%$ & At. $/ \%$ \\
\hline S K & 23.76 & 34.97 \\
\hline Mn K & 42.96 & 36.90 \\
\hline Fe K & 33.29 & 28.13 \\
\hline
\end{tabular}




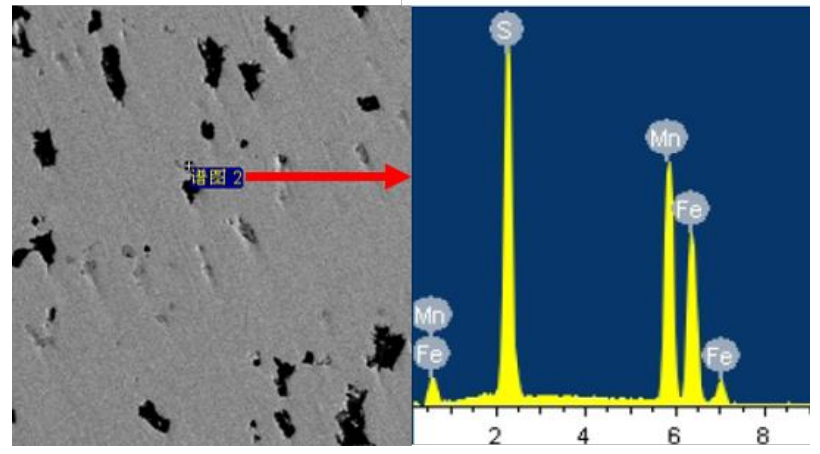

Fig. 4. SEM morphology and EDS spectrum of inclusion

Further observation by scanning electron microscope and semi-quantitative analysis of the series-shaped inclusions by matched energy-dispersive X-ray spectroscopy showed that the composition of the smallparticle inclusions was mainly sulphur-manganese compounds, in which the atomic percentage of $\mathrm{S}$ reached $34.9 \%$, as shown in Fig. 4 and Table 3.

\subsubsection{Cause analysis}

$\mathrm{S}$ is an anti-graphitized element in malleable iron that forms a compound with $\mathrm{Mn}$. Due to the excessive $\mathrm{S}$ element content in suspension clamp A, too much sulphur-manganese compound was formed, and these inclusions were distributed in the matrix in the form of chain, which segmented the continuity of malleable iron matrix, resulting in brittle fracture along the chain inclusions of suspension clamp A.

\subsection{Flake graphite}

The model of suspension clamp B is consistent with that of suspension clamp A, and the fracture position and appearance characteristics are similar to A in Fig. 2.

\subsubsection{Component testing}

Table 4. Components of the suspension clamp B.

\begin{tabular}{|c|c|c|}
\hline Element & Content $\%$ & $\begin{array}{c}\text { Recommended } \\
\text { range } / \%\end{array}$ \\
\hline $\mathrm{C}$ & 2.62 & $2.40-2.80$ \\
\hline $\mathrm{Si}$ & 1.23 & $1.20-2.00$ \\
\hline $\mathrm{Mn}$ & 0.49 & $0.30-0.60$ \\
\hline $\mathrm{S}$ & 0.12 & $\leqslant 0.20$ \\
\hline $\mathrm{P}$ & 0.10 & $\leqslant 0.10$ \\
\hline $\mathrm{Fe}$ & Remain & Remain \\
\hline
\end{tabular}

The component testing results of the suspension clamp B were shown in Table 4. All the content of elements are in accordance with conventional requirements of black heart malleable iron.

\subsubsection{Hardness measurement}

The Brinell hardness of suspension clamp B was measured. The result was shown in Table 5.

Table 5. Brinell hardness of suspension clamp B.

\begin{tabular}{|c|c|c|}
\hline Test number & Test Value/HB & \multirow{2}{*}{ Standard/HB } \\
\hline First & 130 & \multirow{2}{*}{$\leqslant 150$} \\
\cline { 1 - 2 } Second & 132 & \\
\hline Third & 116 & \\
\cline { 1 - 2 } Fourth & 113 & \\
\hline Fifth & 125 & \\
\hline
\end{tabular}

The hardness value of suspension clamp B is between $113 \mathrm{HB}$ and $132 \mathrm{HB}$ which conform to the standard requirements of DL/T768.1-2002 Malleable Iron.

\subsubsection{Microstructure analysis}

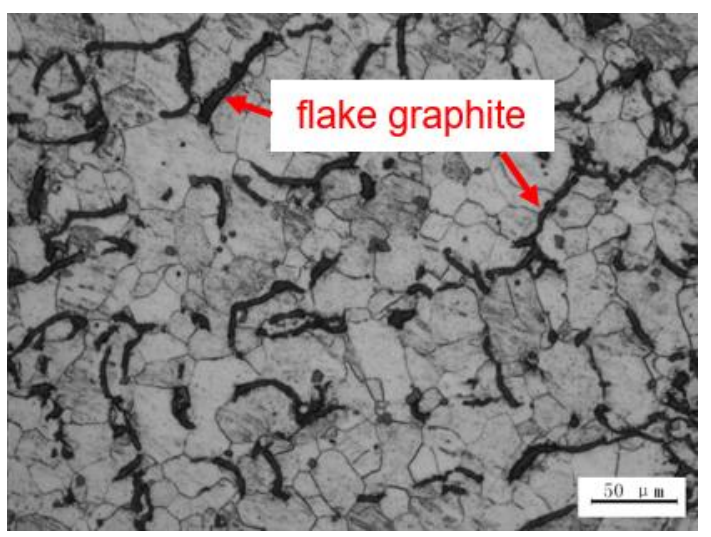

Fig. 5. The metallographic structure of suspension clamp B with flake graphite.

As we can see from Fig. 5, the metallographic structure of suspension clamp B was composed of ferrite and flake graphite, and flake graphite was distributed on the grain boundary of the matrix, showing a reticular structure. It did not meet the requirements of black heart malleable iron in GB/T 9440-2010.

\subsubsection{Cause analysis}

Malleable cast iron is formed by the annealing of white cast iron blank. The $\mathrm{C}$ element in the structure of the 
blank is generally in the form of cementite, and there is no free graphite. After graphitization annealing at high and low temperature, the cementite in the metastable state of the structure was decomposed and transformed into a stable tempered graphite structure. Therefore, the presence of flake graphite in suspension clamp B indicates that white cast iron blank was not completely annealed and there was still a large amount of free carbon. Even if the subsequent annealing treatment was carried out normally, normal metallographic structure could not be obtained. The microstructure of suspension clamp B does not meet the standard requirements of GB/T 9440-2010 Black Heart Malleable Iron, and its mechanical properties deteriorate, resulting in fracture.

\subsection{Cementite network}

Suspension clamp C broke during the test, which was composed of black heart malleable iron.

\subsubsection{Component testing}

Table 6. Components of the suspension clamp C.

\begin{tabular}{|c|c|c|}
\hline Element & Content/\% & $\begin{array}{c}\text { Recommended } \\
\text { range } / \%\end{array}$ \\
\hline $\mathrm{C}$ & 2.48 & $2.40-2.80$ \\
\hline $\mathrm{Si}$ & 1.39 & $1.20-2.00$ \\
\hline $\mathrm{Mn}$ & 0.37 & $0.30-0.60$ \\
\hline $\mathrm{S}$ & 0.10 & $\leqslant 0.20$ \\
\hline $\mathrm{P}$ & 0.05 & $\leqslant 0.10$ \\
\hline $\mathrm{Fe}$ & Remain & Remain \\
\hline
\end{tabular}

The component testing results of the suspension clamp C were shown in Table 6. All the content of elements are in accordance with conventional requirements of black heart malleable iron.

\subsubsection{Hardness measurement}

Table 7. Brinell hardness of suspension clamp B.

\begin{tabular}{|c|c|c|}
\hline Test number & Test Value/HB & Standard/HB \\
\hline First & 128 & \\
\cline { 1 - 2 } Second & 123 & \multirow{2}{*}{$\leqslant 150$} \\
\hline Third & 138 & \\
\hline
\end{tabular}

\begin{tabular}{|c|c|}
\hline Fourth & 134 \\
\hline Fifth & 121 \\
\hline
\end{tabular}

The Brinell hardness of suspension clamp $\mathrm{C}$ was measured. The result was shown in Table 7 . The test values are distributed in the range of $121 \mathrm{HB}$ to $138 \mathrm{HB}$ which conform to the standard requirements of DL/T768.1-2002 malleable iron.

\subsubsection{Microstructure analysis}

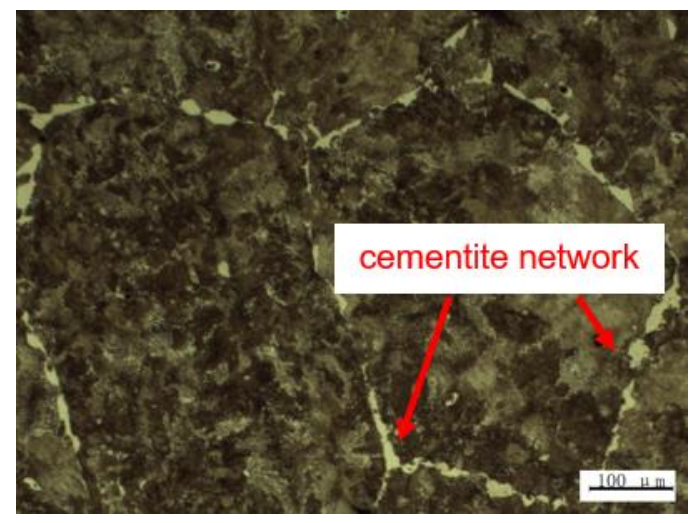

Fig. 6. The metallographic structure of suspension clamp C with cementite network.

The microstructure of suspension clamp $\mathrm{C}$ is a combination of ferrite and cementite network as shown in Fig. 6.

\subsubsection{Cause analysis}

The cementite in the suspension clamp $\mathrm{C}$ are distributed in a network, which divides the continuity of the matrix and leads to the fracture of the clip.

Normally, most or all of the matrix of black heart malleable iron should be ferrite. However, when the annealing temperature is too low or the annealing holding time is too short, there may be residual pearlite or cementite in the matrix. According to Metallographic Atlas of Metal Materials, the first stage (high temperature stage, $920-980^{\circ} \mathrm{C}$ ) will have eutectic cementite in the matrix if the annealing temperature is low or the insulation is insufficient. In the intermediate cooling stage, the secondary cementite will be precipitated in the matrix if the cooling speed is too fast. If the residence time is too long in the process of low temperature cooling, the tertiary cementite will be further precipitated in the matrix. So, the emergence of cementite network in suspension clamp $\mathrm{C}$ indicates that the annealing treatment has not been strictly carried out.

\section{Conclusion}

1) The abnormal microstructure of suspension clamp is closely related to its impurity content, blank and annealing treatment. As analyzed above: too high $\mathrm{S}$ 
content will lead to the occurrence of chain sulfide inclusion; incomplete annealing of white cast iron blank will lead to the distribution of flake graphite among matrix crystals; and annealing temperature, holding time and cooling rate will affect the precipitation of cementite. These abnormal structures divide the continuity of the matrix of the suspension clamp and reduce its mechanical properties.

2) The suspension clamp is a small piece of hardware in overhead power lines, but the accident loss caused by its defect is very expensive. In order to improve the operation stability of the transmission line, it is necessary to carry out the supervision and inspection of hardware before use, and prevent the defective equipment and materials from entering the grid with "disease".

\section{References}

1. Jier Dong. Handbook of Electric Power Hardware 3rd Edition (China Electric Power Press, Beijing, 2010)

2. Jiong-hui Li, Decheng Lin. Metallographic Atlas of Metal Materials (Machinery Industry Press, Beijing, 2006)

3. National technical committee. Standardization of Overhead Lines (power fittings), DL/T 768.1-2002 (China Power Press, Beijing, 2002)

4. National technical committee. Casting Standardization, GB/T 9440-2010 Malleable Cast Iron (China Standard Press, Beijing, 2010)

5. Liu Chun, Yuanfu Tang, Kejian Ouyang, Yunlong Liu, Hunan Electric Power. 37(02), 46-50+63(2017) 